Pesq. Vet. Bras. 37(1):91-96, janeiro 2017

DOI: $10.1590 / \mathrm{S} 0100-736 \mathrm{X} 2017000100015$

\title{
Estudo comparativo da resistência mecânica da força de compressão entre biomateriais naturais, sintéticos e mistos ${ }^{1}$
}

\author{
Josimar Del C. Catello², Renata G.S. Dória3 ${ }^{3}$ Paulo Fantinato Neto ${ }^{3}$, Lázaro M. \\ Camargo $^{2}$, Antônio C. Chimano ${ }^{4}$, Kelly C.I. Yamauchi ${ }^{2}$, Carlos E. Ambrosio ${ }^{3}$ \\ e Silvio H. Freitas ${ }^{2,3 *}$
}

\begin{abstract}
Castello J.D.C., Dória R.G.S., Fantinato Neto P., Camargo L.M., Chimano A.C., Yamauchi K.C.I., Ambrosio C.E. \& Freitas S.H. 2017. [Comparative study of mechanical strength of compression between natural, synthetic and mixed biomaterials.] Estudo comparativo da resistência mecânica da força de compressão entre biomateriais naturais, sintéticos e mistos. Pesquisa Veterinária Brasileira 37(1):91-96. Faculdade de Medicina Veterinária, Universidade de Cuiabá, Rua Itália s/n, Jardim Europa, Cuiabá, MT 78065-420, Brazil. E-mail: silviohfreitas@gmail.com

The orthopedic diseases with bone loss are the challenge in both veterinary and human medicine. Therefore, the orthopedist commonly deal with irreducible comminuted fractures of long bones, bone tumors or non-unions, which require repairers surgical procedures, through the segment replacement or bone defect filling with biomaterials. The aim of this research is to evaluate and compare the mechanical strength of natural, synthetic and mixed biomaterials. Seven experimental groups of six test samples each were used: Group 1 rabbit cortical bone (BONE - control); Group 2, bone cement (CO); Group 3, bone cement autoclaved (COA); Group 4, bone cement and dog cortical bone macrofragment (COMaFO); Group 5, bone cement and bone autoclaved macrofragment dog cortical (COMaFOA); Group 6, bone cement and dog cortical bone microfragment (COMIFO) and Group 7, bone cement and dog cortical bone microfragment (COMiFOA). The specimens were subjected to axial compression mechanical tests controlled universal testing machine EMIC $^{\circledR}$. The test was stopped when there was sharp decline in the graph curve indicating failure of the sample. In relation to the maximum force, the COA groups COMaFOA and COMiFOA not statistically different from the control group (BONE; $\mathrm{p}>0.01$ ). Already the $\mathrm{CO}$ groups, $\mathrm{COMaFO}$ and COMIFO difeririram statistically the control group (BONE; $\mathrm{p}<0.01$ ). The relative rigidity, the COMaFOA and COMiFOA groups did not differ statistically from the control group (BONE; $>0.01$ ). Already the CO groups, $\mathrm{COA}, \mathrm{COMaFO}$ and COMIFO differed significantly from the control group (BONE; $\mathrm{p}<0.01$ ). Comparing the deformation, the COMaFo groups COMaFOA and COMIFO not statistically different from the control group (BONE; p $>0.01$ ). Already the CO groups, $\mathrm{COA}$ and COMiFOA differed significantly from the control group (BONE; $<<0.01$ ). It is concluded that only COMaFOA and COMiFOA groups showed very similar mechanical properties to the control group (BONE). Therefore, due to these characteristics, these two biomaterials (COMaFOA e COMiFOA) would be the most suitable as a substitute in the repair of bone defects.
\end{abstract}

INDEX TERMS: Strength, compression, biomaterial, natural, synthetic, mechanical tests, bone defect.

\footnotetext{
${ }^{1}$ Recebido em 20 de abril de 2016.

Aceito para publicação em 9 de agosto de 2016.

${ }^{2}$ Faculdade de Medicina Veterinária (FMV), Universidade de Cuiabá (Unic), Rua Itália s/n, Jardim Europa, Cuiabá, MT 78065-420, Brasil.

${ }^{3}$ Departamento de Medicina Veterinária (ZMV), Faculdade de Zootecnia e Engenharia de Alimentos (FZEA), Universidade de São Paulo
}

(USP), Rua Duque de Caxias Norte 225, Jardim Elite. Pirassununga, SP 13635-900, Brasil. *Autor para correspondência: silviohfreitas@ gmail.com

${ }^{4}$ Laboratório de Bioengenharia (LB), Faculdade de Medicina (FM), Universidade de São Paulo (USP), Avenida dos Bandeirantes 3900, Monte Alegre, Ribeirão Preto, SP 14049-900, Brasil. 
RESUMO.- As afecções ortopédicas com perda de tecido ósseo são um desafio tanto na medicina veterinária quanto na medicina humana. Portanto, não é raro ortopedistas se depararem com fraturas cominutivas irredutíveis de ossos longos, neoplasias ósseas ou não-uniões, que necessitam de procedimentos cirúrgicos reparadores, por meio da substituição de segmento ou preenchimento de falha óssea com o uso de biomateriais. Pretende-se com esta pesquisa avaliar e comparar a resistência mecânica entre biomateriais naturais, sintéticos e mistos. Foram utilizados sete grupos experimentais compostos por seis corpos de provas cada: Grupo 1 , tecido ósseo cortical de coelho (OSSO - controle); Grupo 2, cimento ósseo (CO); Grupo 3, cimento ósseo autoclavado (COA); Grupo 4, cimento ósseo e macrofragmento ósseo cortical de cão (COMaFO); Grupo 5, cimento ósseo e macrofragmento ósseo autoclavado de cortical de cão (COMaFOA); Grupo 6, cimento ósseo e microfragmento ósseo cortical de cão (COMiFO) e Grupo 7, cimento ósseo e microfragmento ósseo cortical de cão (COMiFOA). Os corpos de prova foram submetidos a ensaios mecânicos de compressão axial controlada em máquina universal de ensaio Emic ${ }^{\circledR} .0$ teste era interrompido quando ocorria queda brusca na curva do gráfico indicando falência da amostra. Em relação à Força máxima, os grupos $\mathrm{COA}$, COMaFOA e COMiFOA não diferiram estatisticamente do grupo controle (OSSO; $>0,01$ ). Já os grupos CO, COMaFO e COMiFO diferiram estatisticamente do grupo controle (OSSO; $<<0,01$ ). Quanto a rigidez relativa, os grupos COMaFOA e COMiFOA não diferiram estatisticamente do grupo controle (OSSO; $\mathrm{p}>0,01)$. Já os grupos CO, COA, COMaFO e COMiFO diferiram estatisticamente do grupo controle (OSSO; $\mathrm{p}<0,01$ ). Comparando a deformação, os grupos COMaFo, COMaFOA e COMiFO não diferiram estatisticamente do grupo controle (OSSO; $p>0,01$ ). Já os grupos CO, COA e COMiFOA diferiram estatisticamente do grupo controle (OSSO; $\mathrm{p}<0,01$ ). Conclui-se que apenas os grupos COMaFOA e COMiFOA apresentaram propriedades mecânicas muito semelhantes às do grupo controle (OSSO). Por isso, devido a essas características, esses dois biomateriais (COMaFOA e COMiFOA) seriam os mais indicados como substitutos na reparação de falhas ósseas.

TERMOS DE INDEXAÇÃO: Resistência mecânica, compressão, biomaterial natural, biomaterial sintético, ensaios mecânicos, falha óssea.

\section{INTRODUÇÃO}

As afecções ortopédicas envolvendo fraturas, além das técnicas ortopédicas de estabilização de fragmentos ósseos, também podem necessitar de procedimentos que necessitam de substituição de tecido ósseo. Uma das principais opções para o tratamento dessas afecções é a substituição de um segmento ou o preenchimento de falha óssea, utilizando biomateriais natural ou sintético (Ranzani et al. 1996, Rezende et al. 1998, Alievi et al. 2007, Freitas et al. 2013). A melhor opção para se tratar as falhas ósseas recai sobre o uso de biomaterial autógeno, ou seja, auto-enxerto, já que acelera a cicatrização óssea. No entanto, há o inconveniente de aumentar a morbidade, a dor, os tempos cirúrgico e anestésico e de lesar estruturas normais, além de não fornecer volume suficiente para reparar grandes falhas ósseas (Friedlaender 1982, Melo et al. 1998, Freitas et al. 2012).

Vários biomateriais naturais têm sido pesquisadas para contribuir no reparo de falhas ósseas. Eles podem ser obtidos a partir de animais da mesma espécie, ou seja, biomaterial alógeno, ou de espécie diferente, isto é, biomaterial heterógeno. Apesar de serem biologicamente inferiores ao biomaterial autógeno, eles têm sido bastante utilizados na ortopedia reparadora, com resultados satisfatórios (Lane \& Sandhu 1987, Moraes et al. 2004, Tadjoedin et al. 2003, Carneiro et al. 2005, Freitas et al. 2008). As falhas ósseas também podem ser completa e eficientemente preenchidas por biomateriais sintéticos, como polimetilmetacrilato (Kawano et al. 1998, Rezende et al. 1998, Weinfeld et al. 1999, Rahal et al. 2000, Braz et al. 2003, Fernandes et al. 2004, Moreira et al. 2014).

O biomaterial misto, resultante da combinação de um biomaterial natural, tecido ósseo, e de um sintético, polimetilmetacrilato, de uma forma geral, apresenta requisitos básicos como promover a osteoindução, que se dá pela formação de osso a partir de células osteoprogenitoras, oriundas das células mesenquimatosas primitivas sob a influência de um ou mais fatores indutores da matriz óssea; a osteocondução, que se caracteriza pelo crescimento ósseo por meio de aposição de tecido ósseo subjacente na presença de osso ou células mesenquimatosas indiferenciadas, além de serem biocompatíveis, não carcinogênicos, atóxicos, não antigênicos e sem persistência de processos inflamatórios (Alexander 1987, Akamoto \& Trento 2002, Yacubian-Fernandes et al. 2004, Raposo-do-Amaral et al. 2010, Freitas et al. 2014).

Uma opção para a reparação das falhas ósseas seria o uso de biomateriais naturais, sintéticos ou mistos que apresentassem propriedades osteogênicas, osteoindutora e osteocondutora, que proporcionassem sustentação mecânica, de fácil aquisição, baixo custo, que não necessitassem de material especializado para preservação, e que preenchessem completamente a falha óssea, eliminando problemas inerentes ao biomaterial autógeno (Sinibaldi 1989, Bauer \& Muschler 2000, Alievi et al. 2007, Freitas et al. 2012, Fernandes et al. 2014).

Para que um biomaterial possa ser utilizado como substituto ósseo, além de ser biocompatível, é necessário que a resistência mecânica seja compatível com a do leito receptor. Para isso, torna-se necessário a realização de ensaios mecânicos específicos, que depende do tipo de material a ser testado, da finalidade a que se destina, do tipo de esforço ao qual será submetido e, também, das propriedades do biomaterial (França et al. 2008, Singh et al. 2013, Ueno et al. 2015). 0 teste mecânico de compressão é um dos mais indicado para avaliar a resistência de um biomaterial, que pode ser destrutivo ou não (Amendola et al. 2008, Nandi et al. 2010, Rocha et al. 2011, Sonagli et. 2011). Sendo assim, o objetivo deste trabalho foi avaliar e comparar a resistência mecânica entre biomateriais naturais, sintéticos e mistos, submetidos a forças de compressão axial controlada. 


\section{MATERIAL E MÉTODOS}

Os corpos de prova para o experimento foram preparados na Faculdade de Medicina Veterinária (FMV) da Universidade de Cuiabá (UNIC), Cuiabá-MT e no Departamento de Medicina Veterinária (DMV) da Faculdade de Zootecnia e Engenharia de Alimentos (FZEA) da Universidade de São Paulo (USP), Campus de Pirassununga-SP e os ensaios mecânicos foram realizados no Laboratório de Bioengenharia (LB) da Faculdade de Medicina (FM) da Universidade de São Paulo (USP) - Ribeirão Preto, SP.

Para o preparo dos corpos de prova constituídos de tecido ósseo cortical de diáfise de fêmur de coelho do Grupo 1 (OSSO), foram coletados dois fêmures de um coelho com 4 meses de idade, que foi abatido no frigorífico da FZEA da USP, Campus de Pirassununga-SP. Após a remoção dos tecidos moles adjacentes, com o uso de uma serra dupla paralela distando $7 \mathrm{~mm}$ uma Lâmina da outra, foram removidos três segmentos da diáfise de cada fêmur ( $7 \mathrm{~mm}$ de comprimento $\mathrm{x} 7 \mathrm{~mm}$ de diâmetro externo menor) (crânio-caudal) x $1 \mathrm{~mm}$ espessura).

Para confecção dos corpos de prova constituídos de cimento ósseo "polimetilmetacrilato" do Grupo 2 (CO), uma mistura pastosa de polimetilmetacrilato (polímero e monómero) foi injetada em um gabarito cilíndrico de $7 \mathrm{~mm}$ de diâmetro por $60 \mathrm{~mm}$ de comprimento. Após polimerização, o cilindro de CO foi removido do gabarito e fixado no cabeçote fixo de um torno mecânico paralelo, para realizar o faceamento, abertura de um orifício central ( $4 \mathrm{~mm}$ de diâmetro) em toda sua extensão, utilizando uma sequência de brocas (2, 3 e $4 \mathrm{~mm}$ ) e, também, com auxílio do torno, foram removidos seis segmentos do cilindro preparado $(7 \mathrm{~mm}$ comprimento $\mathrm{x} 7 \mathrm{~mm}$ diâmetro externo $\mathrm{x} 4 \mathrm{~mm}$ diâmetro interno $\mathrm{x}$ $1,5 \mathrm{~mm}$ espessura de parede).

Para a confecção dos corpos de prova constituídos de cimento ósseo autoclavado do Grupo 3 (COA), além dos procedimentos empregados na confecção do corpo de prova CO, eles fora autoclavados a uma temperatura de $121^{\circ} \mathrm{C}$ por 15 minutos de exposição (Freitas et al. 2014).

As partículas de macrofragmentos ósseos corticais (MaFO) e microfragmentos ósseos corticais (MiFO) foram obtidas de diáfise de tíbia de cão preservada em glicerina a 98\%, que permaneceram nesse meio por um período não inferior a 30 dias. Após hidratação em solução salina a $0,9 \%$, a diáfise foi particulada, fragmentada, e separada com o uso de duas peneiras, a primeira com furos de $2 \mathrm{~mm}$ e a segunda com furos de $1 \mathrm{~mm}$. Para obtenção dos (MaFO), coletou-se os fragmentos ósseos que passaram pela peneira maior $(2 \mathrm{~mm})$ e que ficaram retidos na peneira menor (1mm). Já para obtenção dos (MiF0), foram utilizados todos os fragmentos ósseos que passaram pela peneira com furos de $1 \mathrm{~mm}$.

Para a confecção dos corpos de prova constituídos de cimento ósseo e macrofragmentos ósseos corticais de tíbia de cão do Grupo 4 (COMaFO), uma mistura de MaFO e de CO (polímero - polimetilmetacrilato), na mesma proporção, foi adicionada a porção líquida, o monômero de polimetilmetacrilato, até atingir uma consistência pastosa que foi injetada em um gabarito de $7 \mathrm{~mm}$ de diâmetro por $60 \mathrm{~mm}$ de comprimento. Após polimerização, o cilindro contendo COMaFO foi removido do gabarito e fixado no cabeçote fixo de um torno mecânico paralelo, para realizar o faceamento, abertura de um orifício central de $4 \mathrm{~mm}$ de diâmetro, em toda sua extensão, utilizando uma sequência de brocas (2, 3 e 4mm) e, também com auxílio do torno, foram removidos seis segmentos do cilindro preparado $(7 \mathrm{~mm}$ comprimento $\mathrm{x} 7 \mathrm{~mm}$ diâmetro externo $\mathrm{x} 4 \mathrm{~mm}$ diâmetro interno $\mathrm{x}$ 1,5mm espessura de parede)

Para a confecção dos corpos de prova constituídos de cimento ósseo autoclavado do Grupo 5 (COMaFOA), além dos procedimentos empregados na confecção do corpo de prova COMaFO, eles foram autoclavados a uma temperatura de $121^{\circ} \mathrm{C}$ por 15 minutos de exposição.

Para a confecção dos corpos de prova constituídos de cimento ósseo e macrofragmentos ósseos corticais de tíbia de cão do Grupo 6 (COMiFO), uma mistura de MiFO e de CO (polímero - polimetilmetacrilato), na mesma proporção, foi adicionada a porção líquida (monômero - polimetilmetacrilato), até atingir uma consistência pastosa que foi injetada em um gabarito de $7 \mathrm{~mm}$ de diâmetro por $60 \mathrm{~mm}$ de comprimento. Após polimerização, o cilindro de CO foi removido do gabarito e fixado no cabeçote fixo de um torno mecânico paralelo, para realizar o faceamento, abertura de um orifício central de $4 \mathrm{~mm}$ de diâmetro, em toda sua extensão, utilizando uma sequência de brocas (2, 3 e 4mm) e, também, com auxílio do torno, foram removidos seis segmentos do cilindro preparado ( $7 \mathrm{~mm}$ comprimento x $7 \mathrm{~mm}$ diâmetro externo x $4 \mathrm{~mm}$ diâmetro interno x 1,5mm espessura de parede).

Para a confecção dos corpos de prova constituídos de cimento ósseo autoclavado do Grupo 7 (COMiFOA), além dos procedimentos empregados na confecção do corpo de prova COMiFO, eles foram autoclavados a uma temperatura de $121^{\circ} \mathrm{C}$ por 15 minutos de exposição).

Os ensaios mecânicos dos corpos de prova dos grupos experimentais foram realizados em uma máquina universal de ensaio $\left(\right.$ Emic $^{\circledR}$, acoplada com Software Tesc 3.13 e célula de carga de $10.000 \mathrm{~N}$, pré-carga de $10 \mathrm{~N}$ e tempo de acomodação de 30 segundos).

Após posicionar o corpo de prova sobre uma base circular plana, a máquina de ensaios era ligada e um eixo de carga posicionado na porção superior acionado até que os parâmetros de força em Newtons $(\mathrm{N})$ e deslocamento em milímetros ( $\mathrm{mm}$ ) fossem zerados e o sistema calibrado (Fig.1).

0 ensaio era iniciado com um deslocamento controlado de $1 \mathrm{~mm} / \mathrm{min}$, e os parâmetros de força e deslocamento eram gerados e analisados pela máquina de ensaio e os as informações convertidas em gráficos (França et al. 2008, Sonagli et al. 2011).

A falência total do corpo de prova foi definida quando a curva do gráfico $(\mathrm{N} / \mathrm{mm})$ apresentava-se uma queda brusca durante $o$ ensaio, momento em que o teste era interrompido.

Com os dados obtidos do gráfico força $(\mathrm{N})$ versus deslocamen-

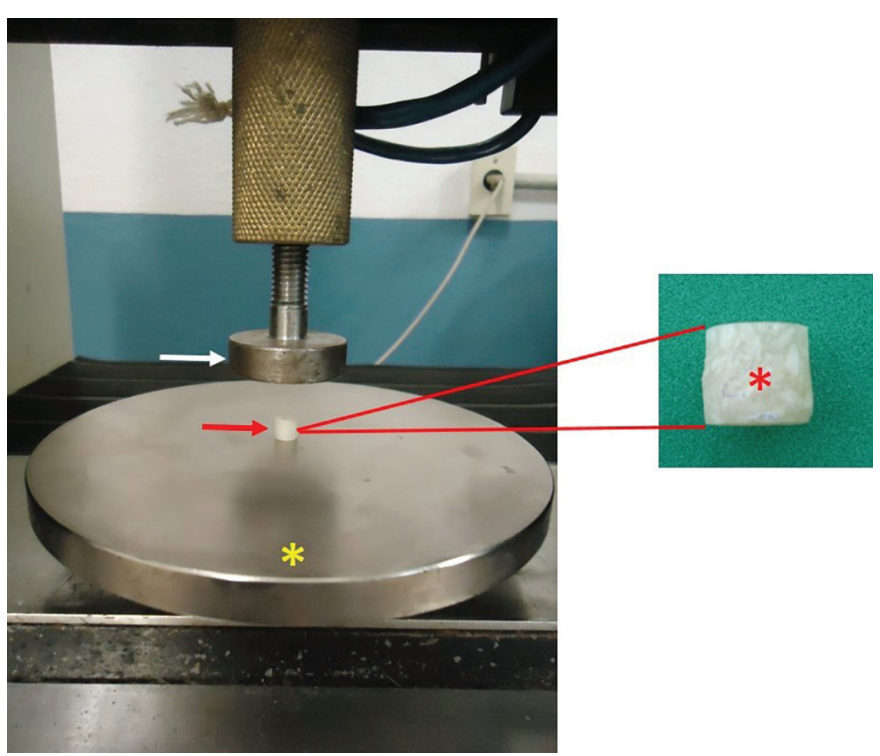

Fig.1. Maquina universal de ensaios. Base plana e circular (asterisco amarelo), corpo de prova (seta vermelha) e eixo de carga (seta branca). Corpo de prova após ensaio mecânico com deformação (asterisco vermelho). 
to (mm), criou-se uma tabela com o resultado de cada grupo experimental (Grupos 1 a 7), com valores mensurados: Força máxima $(\mathrm{N})$, Deslocamento $(\mathrm{mm})$ e a Rigidez $(\mathrm{N} / \mathrm{mm})$.

Os dados obtidos dos ensaios mecânicos de compressão axial controlada dos corpos de provas naturais, sintéticos e mistos foram então analisados utilizando o programa estatístico Statistical Analysis System (SAS, 2011), com prévia verificação da normalidade dos resíduos pelo teste de Shapiro-Wilk (PROC UNIVARIATE). As variáveis que não atenderam às premissas estatísticas foram submetidas à transformação logarítmica [Log $(\mathrm{X}+1)]$. Os dados originais ou transformados, quando este procedimento foi necessário, foram submetidos à análise de variância (PROC GLM) seguido do teste de Tukey (MEANS statment). Considerou-se grupo controle os implantes naturais em relação aos implantes sintéticos e mistos e, em todas as análises estatísticas, o nível de significância considerado foi de $1 \%$.

\section{RESULTADOS E DISCUSSÃO}

Como a região diafisária do fêmur de coelho, ao corte transversal, é elíptica, decidiu-se em adotar o comprimento do menor diâmetro, sentido crânio-caudal do osso, para construção dos corpos de prova. No caso dos dois fêmures utilizados para confecção dos corpos de provas naturais (OSSO), que também foi adotado como controle, o menor diâmetro externo apresentou-se $7 \mathrm{~mm}$ de comprimento. De posse desse número, pode-se construir os corpos de prova cilíndricos sintéticos e mistos, com dimensões de: $7 \mathrm{~mm}$ comprimento $\times 7 \mathrm{~mm}$ diâmetro externo $\times 4 \mathrm{~mm}$ diâmetro interno x 1,5mm de espessura de parede. A opção pelo menor diâmetro externo da diáfise femoral, foi devido ao fato de que a escolha pelo maior diâmetro externo, sentido látero-medial do osso, com $12 \mathrm{~mm}$, poderia proporcionar a confecção de corpo de prova cilíndrico, ou seja, um implante, com dimensões excessivas, que poderia, ao teste mecânico de compressão, fornecer resultados muito superiores ao do grupo controle (OSSO).

Para uso na reparação de falhas ósseas, os implantes têm que ser esterilizados, e as melhores opções são com o uso de radiação gama e óxido de etileno (Alves et al. 2010). Além, desses dois métodos, a esterilização também pode ser realizada com o uso de autoclave, que foi a técnica utilizada neste estudo para esterilizar os corpos de prova (Freitas et al. 2014, Moreira et al. 2014).

Adotando a mesma metodologia utilizada por França et al. (2008), Iwaki et al. (2011) e Sonagli et al. (2011), após posicionamento e acomodação do corpo de prova cilíndrico na base plana da máquina universal, o ensaio era iniciado com um deslocamento controlado de $1 \mathrm{~mm} / \mathrm{min}$ até a sua falência total, momento em que a curva do gráfico (N/ $\mathrm{mm}$ ) apresentava-se uma queda brusca, e o teste mecânico era interrompido.

0 implante ou biomaterial, para que possa ser utilizado como substituto ósseo, além de ser compatível ao leito receptor, é necessário que a resistência mecânica seja compatível com a do leito receptor. Para isso, torna-se necessário a realização de ensaios mecânicos específicos, que depende do tipo de material a ser testado, da finalidade a que se destina, do tipo de esforço ao qual será submetido e, também, das propriedades do biomaterial (França et al. 2008, Singh et al. 2013, Ueno et al. 2015). Como o esqueleto apendicular dos animais está sob ação de um conjunto de forças, dentre elas a de compressão, o teste mecânico de compressão axial, atualmente, é o mais utilizado para avaliar a resistência mecânica de biomaterial, principalmente os cilíndricos (Amendola et al. 2008, Alves et al. 2010, Sonagli et al. 2011).

Os valores médios de força máxima $(\mathrm{N})$, rigidez relativa $(\mathrm{N} / \mathrm{mm})$ e deformação (mm) e desvio padrão, obtidos pelo ensaio de compressão axial controlada dos Grupos Experimentais estão apresentados no Quadro 1.

Quanto a força máxima (Fig.2), que é a força necessária para deformar uma amostra até a sua falência total, os grupos COA, COMaFOA e COMiFOA não diferiram estatisticamente do grupo controle (OSSO; $p>0,01$ ). Já os grupos CO, COMaFO e COMiFO diferiram estatisticamente do grupo controle (OSSO; $\mathrm{p}<0,01)$.

\section{Quadro 1. Valores médios e desvio padrão de cada grupo} experimental, obtidos a partir dos testes mecânicos de compressão axial controlada

\begin{tabular}{lccc}
\hline Amostras & $\begin{array}{c}\text { Força máxima } \\
(\mathrm{N})\end{array}$ & $\begin{array}{c}\text { Rigidez relativa } \\
(\mathrm{N} / \mathrm{mm})\end{array}$ & $\begin{array}{c}\text { Deformação } \\
(\mathrm{mm})\end{array}$ \\
\hline OSSO & $2400,00 \pm 352,90$ & $5559,00 \pm 1772,00$ & $0,5255 \pm 0,2385$ \\
CO & $1957,00 \pm 245,00^{*}$ & $2852,00 \pm 836,00^{*}$ & $0,9514 \pm 0,2884^{*}$ \\
COA & $2319,00 \pm 88,55$ & $2915,00 \pm 450,50^{*}$ & $1,0460 \pm 0,1556^{*}$ \\
COMaFO & $1945,00 \pm 119,40^{*}$ & $2945,00 \pm 390,40^{*}$ & $0,8357 \pm 0,0922$ \\
COMiFO & $1651,00 \pm 127,50^{*}$ & $2844,00 \pm 519,30^{*}$ & $0,7364 \pm 0,1051$ \\
COMaFOA & $2363,00 \pm 134,50$ & $3770,00 \pm 347,30$ & $0,7961 \pm 0,0769$ \\
COMiFOA & $2518,00 \pm 120,40$ & $3369,00 \pm 497,20$ & $0,9670 \pm 0,2054^{*}$
\end{tabular}

* Diferem estatisticamente do controle (OSSO). Fonte: Laboratório de Bioengenharia da Faculdade de Medicina da Universidade de São Paulo.

\section{Força máxima de compressão}

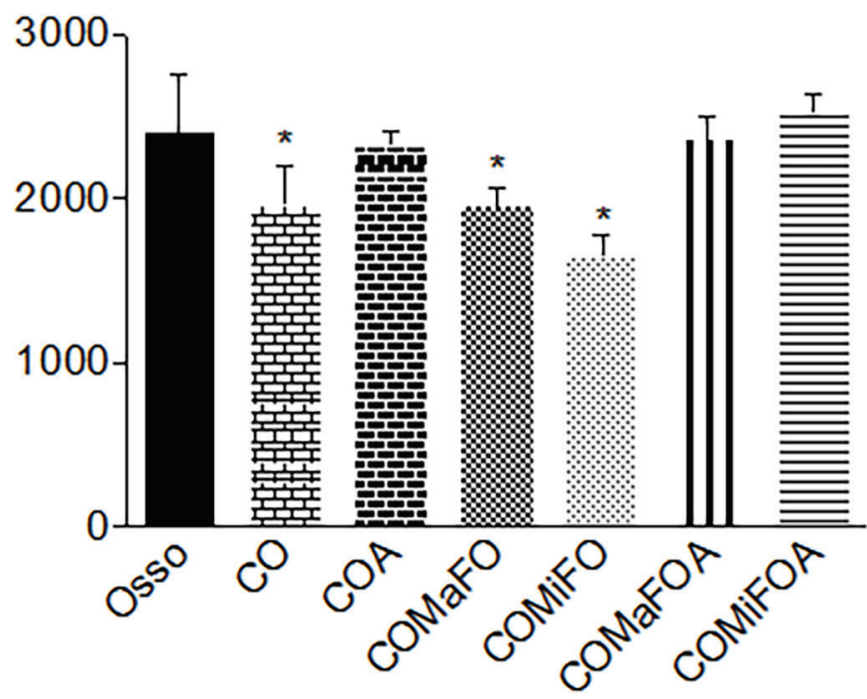

Fig.2. Força máxima de compressão (Média \pm Desvio padrão) das diferentes amostras testadas. Osso (controle); Cimento ósseo (CO); Cimento ósseo autoclavado (COA); Cimento ósseo com macrofragmentos ósseos (COMaFO); Cimento ósseo com microfragmentos ósseos (COMiFO); Cimento ósseo com macrofragmentos ósseos autoclavado (COMaFOA) e Cimento ósseo com microfragmentos ósseos autoclavado (COMiFOA). * Diferem estatisticamente do osso (controle; $\mathrm{p}<0,01$ ). 


\section{Rigidez}

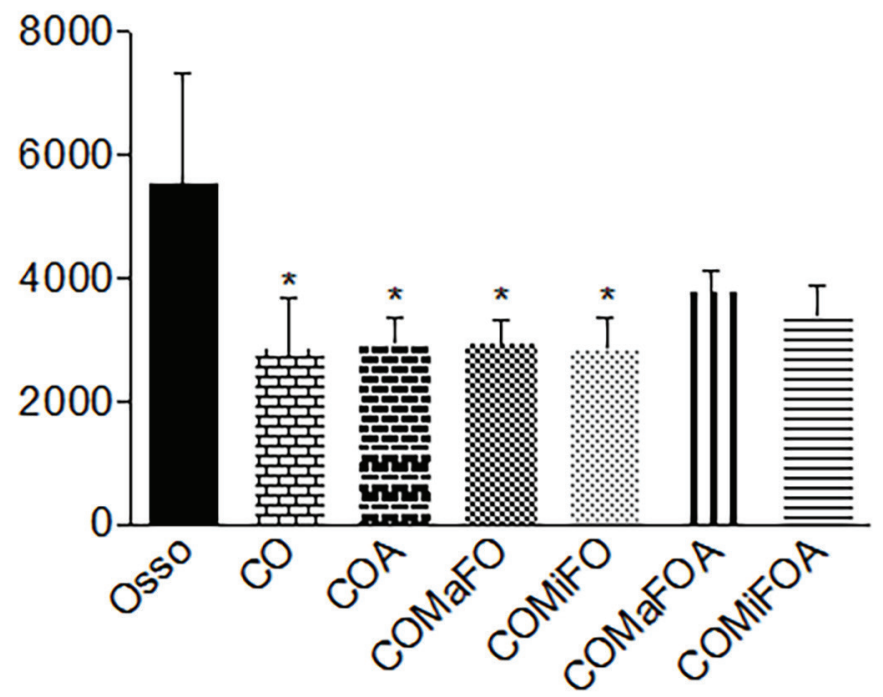

Fig.3. Rigidez relativa (Média \pm Desvio padrão) das diferentes amostras testadas. Osso (controle); Cimento ósseo (CO); Cimento ósseo autoclavado (COA); Cimento ósseo com macrofragmentos ósseos (COMaFO); Cimento ósseo com microfragmentos ósseos (COMiFO); Cimento ósseo com macrofragmentos ósseos autoclavado (COMaFOA) e Cimento ósseo com microfragmentos ósseos autoclavado (COMiFOA). * Diferem estatisticamente do osso (controle; $p<0,01$ ).

\section{Deformação}

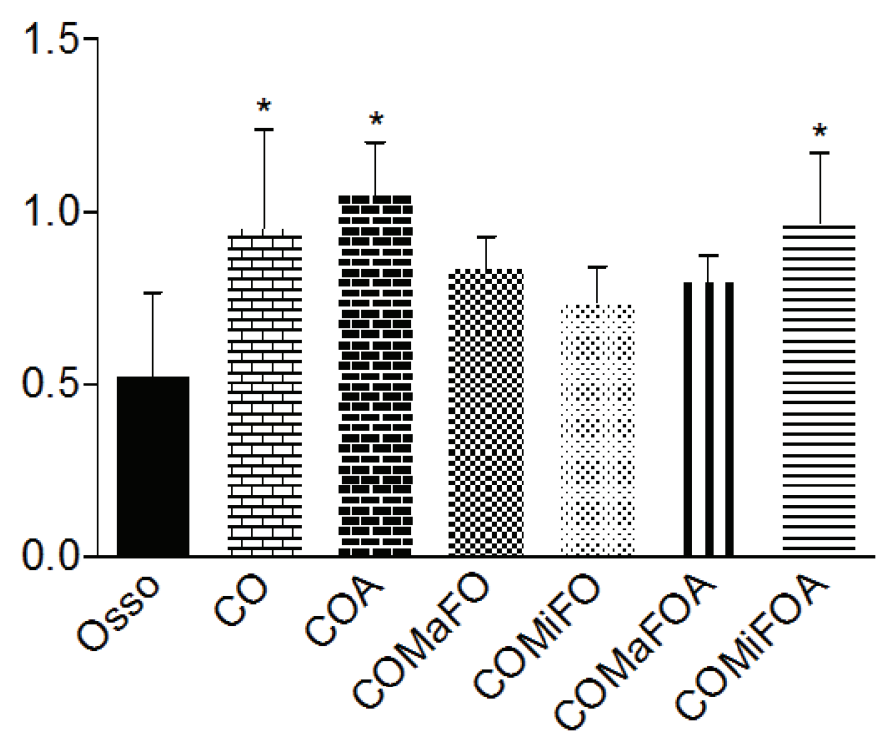

Fig.4. Deformação (Média \pm Desvio padrão) das diferentes amostras testadas. Osso (controle); Cimento ósseo (CO); Cimento ósseo autoclavado (COA); Cimento ósseo com macrofragmentos ósseos (COMaFO); Cimento ósseo com microfragmentos ósseos (COMiFO); Cimento ósseo com macrofragmentos ósseos autoclavado (COMaFOA) e Cimento ósseo com microfragmentos ósseos autoclavado (COMiFOA). *Diferem estatisticamente do osso (controle; $\mathrm{p}<0,01$ ).

A rigidez relativa (Fig.3), que é a capacidade da amostra de absorver energia até a sua falência total, os grupos COMaFOA e COMiFOA não diferiram estatisticamente do gru- po controle (OSSO; p>0,01). Já os grupos CO, COA, COMaFO e COMiFO diferiram estatisticamente do grupo controle (OSSO; p<0,01).

Já a deformação (Fig.4), que é o quanto a amostra se reduz de tamanho até a sua falência total, os implantes COMaFo, COMaFOA e COMiFO não diferiram estatisticamente do grupo controle (OSSO; p>0,01). Já os grupos CO, COA e COMiFOA diferiram estatisticamente do grupo controle (OSSO; $\mathrm{p}<0,01$ ).

Os ensaios mecânicos de compressão axial foram concluídos, nãos sendo observado nenhum escorregamento de corpo de prova da base circular plana, durante o acionamento do eixo de carga para realizar os ensaios mecânicos de compressão axial controlada até a falência total da amostra, demostrando que a metodologia empregada foi adequada, pois o conjunto formado pelo corpo de prova-máquina de ensaio manteve-se estável.

Após os ensaios mecânicos, observou-se deformação estrutural em todos os corpos de prova dos grupos experimentais, com redução de comprimento e aumento de diâmetro externo.

\section{CONCLUSÕES}

Dentre os grupos experimentais, somente os do COMaFOA e do COMiFOA apresentaram propriedades mecânicas semelhantes às do grupo controle (OSSO).

Por isso, devido a essas características, esses dois biomateriais seriam os mais indicados como substitutos na reparação de falhas ósseas.

\section{REFERÊNCIAS}

Akamoto T. \& Trento C.L. 2002. Implante homógeno de matriz dentinária desmineralizada conservada em glicerina a 98\% em alvéolo dental: estudo microscópico em rato. Revta Ciênc. Odont. 5:33-43.

Alexander J.W. 1987. Bone grafting. Vet. Clin. North Am. Small Anim. Pract. 17:811-819.

Alievi M.M., Schossler J.E.W., Guimarães L.D., Oliveira A.N.C., Traeslel C.K. \& Ferreira P. 2007. Implante ósseo cortical alógeno conservado em mel na reconstrução de falha óssea diafisária em fêmur de cães: avaliação clínica e radiográfica. Ciência Rural 37:450-457.

Alves E.G.L., Rezende C.M.F., Oliveira H.P., Borges N.F., Mantovani P.F. \& Rosado I.R. 2010. Emprego experimental da placa de compósito poli-hidroxibutirado/hidroxiapatita na fixação femoral em gatos. Arq. Bras. Med. Vet. Zootec. 62:1128-1134.

Amendola G.F., Raiser A.G., Soares J.M.D. \& Beckmann D.V. 2008. Aspectos biomecânicos compressivos de diáfises femorais caninas conservadas em glicerina a 98\% ou em mel. Ciência Rural 38:1341-1345.

Bauer T.W. \& Muschler G.F. 2000. Bone Graft Materials. Clin. Orthop. 37:10-27.

Braz F., Rahal S.C., Rocha N.S., Taga E. \& Biasi F. 2003. Emprego de matriz óssea orgânica bovina e hidroxiapatita no reparo de defeito induzido em crânio de ratos. Acta Cir. Bras. 18:1-12.

Carneiro E., Garcia R.B., Oliveira R.C., Moraes F.G., Menezes R., Letra A., Canova G.C., Cestari T.M. \& Granjeiro J.M. 2005. Microscopic and radiographic analysis of the effect of particle size of demineralized bovine cancellous bone matrix on the repair of bone defects in femurs of rabbits. J. Appl. Oral Sci. 13:157-162.

Fernandes A.Y., Laronga P.R., Coelho R.A., Ducati L. G. \& Silva M.V. 2004. Prototipagem como forma alternativa para realização de cranioplastia com metilmetacrilato. Arq. Neuropsiquiatr. 62:865-868.

Fernandes M.B., Guimarães J.A., Casado P.L., Cavalcanti A.S., Gonçalves N.N., Ambrósio C.E., Rodrigues F., Pinto A.C., Miglino M.A. \& Duarte M.E. 2014. The effect of bone allografts combined with bone marrow stromal 
cells on the healing of segmental bone defects in a sheep model. BMC Vet. Res. 10(1):36. doi: 10.1186/1746-6148-10-36

França L.C.M., Oliveira M.P.C., Falcom R.S., Rugani M.G., Werlang P.M., Aguiar L.F. \& Pinto R.Z.A. 2008. Estudo biomecânico comparativo da resistência às forças de compressão entre os parafusos pediculares poliaxias e monoaxiais. Coluna/Columna 7:133-138.

Freitas S.H., Dória R.G.D., Mendonça F.S., Evêncio Neto J. \& Camargo L.M. 2008. Aspecto radiológico de heteroenxerto ósseo cortical fragmentado na reparação de falhas ósseas em coelhos. Revta Bras. Ciênc. Vet. 15:107-110

Freitas S.H., Dória R.G.S., Mendonça F.S., Santos M.D., Moreira R., Simões R.S., Camargo L.M., Marques A.T.C. \& Simões M.J. 2012. Tomografia computadorizada da matriz óssea mineralizada heteróloga fragmentada e metilmetacrilato na reparação de falhas ósseas. Arq. Bras. Med. Vet. Zootec. 64:1547-1554.

Freitas S.H., Dória R.G.D., Mendonça F.S., Camargo L.M., Presser C.I., Santos M.D., Shimano A.C. \& Ambrósio C.E. 2013. Avaliação morfológica e por imagem radiográfica da matriz óssea mineralizada heteróloga fragmentada e metilmetacrilato preservados em glicerina para reparação de falhas ósseas em tíbias de coelhos. Pesq. Vet. Bras. 33:765-770.

Freitas S.H., Dória R.G.S., Mendonça F.S., Santos M.D., Engrácia Filho J.R., Vidane A.S., Marques A.T.C. \& Ambrósio C.E. 2014. Tomographic imaging of fragmented cortical bone heteroimplant and methylmethacrylate in segmental bone defect of rabbit tibia. Acta Cir. Bras. 29:794-800.

Friedlaender G.E. 1982. Current concepts review: bone banking. J. Bone Joint Surg. 64:307-311.

Iwaki L.C.V., Iwaqui Filho I., Barbosa M.A.L., Silva J.B. \& Takeshida W.M. 2011. Avaliação da densidade óssea e da resistência à força entre enxertos alógenos com fosfato de cálcio bifásico e tecido ósseo em tíbias de coelhos. Pesq. Bras. Odontoped. Clin. Integr. 11:511-517.

Kawano C.T., Romano Neto O. \& Monteiro A.C. 1998. Classificação dos defeitos ósseos e métodos de correção nas artroplastias primárias de joelho. Revta Bras. Ortop. 33:287-290.

Lane J.M. \& Sandhu H.S. 1987. Current approaches to experimental bone grafting. Orthop. Clin. North Am. 18:213-225.

Melo E.G., Rezende C.M.F., Borges A.P.B. \& Nobrega Neto P.I. 1998. Aloenxerto ósseo cortical: avaliação do seu emprego em tíbia de cão. Arq. Bras. Med. Vet. Zootec. 50:385-394.

Moraes P.C., Padilha Filho J.G., Canola J.C., Santos L.A., Macoris D.G., Alessi A.C., Castro M.B. \& Dória Neto F. 2004. A biocompatibilidade do cimento de fosfato de cálcio implantado no rádio de coelhos. Acta Cir. Bras. 19:351-359.

Moreira R., Dória R.G.S., Camargo L.M., Santos M.D., Minto B.W., De Nardi A.B., Ambrósio C.E. \& Freitas S.H. 2014. Aspecto radiológico e macroscó- pico de matriz óssea mineralizada heteróloga e polimetilmetacrilato autoclavado em falha óssea de tíbia de coelhos. Pesq. Vet. Bras. 34:173-178.

Nandi S.K., Roy S., Mukherjee P., Kundu B., De D.K. \& Basu D. 2010. Hopaedic applications of bone graft \& graft substitutes: a review. Indian. J. Med. Res. 132:15-30.

Rahal S.C., Bergamo F.M.M. \& Ishiy H.M. 2000. Prótese intra-ocular de resina acrílica em cães e gatos. Arq. Bras. Med. Vet. Zootec. 52:319-324.

Ranzani J.J.T., Sampaio G.R., Franco M. \& Castro G.B. 1996. Aplicação de membrana biológica heteróloga conservada em glicerina, na reparação de lesão em coelhos. Vet. Zootec. 8:35-45.

Raposo-do-Amaral C.A.A., Raposo-do-Amaral C.E., Roland F.G., Silva J.V.L., Paschoal G.H.L. \& Silva A.M. 2010. Implantes pré-fabricados customizados nas grandes perdas ósseas do esqueleto craniofacial. Revta Bras. Cir. Craniomaxilofacial 3:175-179.

Rezende C.M.F., Borges A.P.B., Bernis W.O., Melo E.G. \& Nobrega Neto P.I. 1998. Aspecto clínico-cirúrgico e radiográficos da hidroxiapatita sintética na diáfise proximal da tíbia de cães. Arq. Bras. Med. Vet. Zootec. 50:537-545.

Rocha F.S., Ramos L.M.A., Batista J.D., Zanetta-Barbosa D. \& Dechichi P. 2011. Organic bovine graft associated with prp in rabbit's calvaria. Intern. Arch. Otor. 15:208-213.

Singh A.K., Rastogi A. \& Singh V. 2013. Biomechanical comparison of dynamic condylar screw and locking compression plate fixation in unstable distal femoral fractures: an in vitro study. Indian J. Orthop. 47:615-620.

Sinibaldi K. 1989. Evaluation of full cortical allografts in 25 dogs. J. Am. Vet. Med. Assoc. 194:1570-1577.

Sonagli M.A., Graells X.S., Negrisoli M.B., Sonagli M., Benato M.L., Zaninelli E.M., Oliveira L.Y.S. \& Cunha L.A.M. 2011. Estudo biomecânico da fixação pedicular curta na fratura-explosão toracolombar. Coluna/Columna 10:183-187.

Tadjoedin E.S., Tadjoedin E.S., De Lange G.L., Bronckers A.L.J.J., Lyaruu D.M. \& Burge E.H. 2003. Deproteinized cancellous bovine bone (Bio-Osso) as bone substitute for sinus floor elevation: a retrospective, histomorphometrical study of five cases. J. Clin. Periodontol. 30:261-270.

Ueno F.H., Pisani M.J., Machado A.N., Rodrigues F.L., Fujiki E.N. \& Rodrigues L.M.R. 2015. Estudo biomecânico da fixação da fratura sacroilíaca com barras de titânio e parafusos pediculares. Acta Ortop. Bras. 23:154-157.

Weinfeld I., Magalhães L.V. \& Vila N. 1999. Estudo histológico de um novo material (biobone) indicado para reparação óssea. Revta Paul. Odontol. 21:9-10.

Yacubian-Fernandes A., Laronga P.R., Coelho R.A., Ducati L.G. \& Silva M.V. 2004. Prototipagem como forma alternativa para realização de cranioplastia com metilmetacrilato: nota técnica. Arq. Neuropatol. Psiquiatr. 62:865-868. 